\title{
Muhaka icipe, an enigmatic new genus and species of Kleidotomini (Hymenoptera: Figitidae: Eucoilinae) from an East African coastal forest
}

\author{
M.L. Buffington ${ }^{\mathrm{a} *}$ and R.S. Copeland ${ }^{\mathrm{b}, \mathrm{c}}$ \\ ${ }^{a}$ Systematic Entomology Laboratory, ARS/USDA, clo Smithsonian Institution, National \\ Museum of Natural History, Washington, DC, USA; ${ }^{b}$ International Centre of Insect Physiology \\ and Ecology (ICIPE), Nairobi, Kenya; ${ }^{c}$ Division of Invertebrate Zoology, National Museums of \\ Kenya, Nairobi, Kenya
}

(Received 22 January 2015; accepted 15 April 2015; first published online 24 June 2015)

\begin{abstract}
A remarkable new eucoiline genus and species, Muhaka icipe, is described herein. The genus is clearly a Kleidotomini, but is distinguished from other genera in the tribe by a unique head and scutellar morphology. The genus belongs to the 'wedge-head'-syndrome group of species that, to date, is unique to Afrotropical eucoilines. The new genus and species is reminiscent of Stentorceps Quinlan and Nanocthulhu Buffington, but is readily distinguished from these genera. Muhaka was collected from a threatened kaya (sacred forest) of coastal Kenya. The biological importance of this and other kaya forests, as well as their protection, is discussed.

http://www.zoobank.org/urn:lsid:zoobank.org:pub:6918ED2C-69A4-48FC-A1E42B5DFF58E876
\end{abstract}

Keywords: Cynipoidea; head morphology; Afrotropical Region

\section{Introduction}

The coastal forests of Eastern Africa, stretching from southern Somalia to Mozambique, make up one of only eight biodiversity hotspots in Africa (CI 2013). Dotted along the East African coast are remnant indigenous forests of varying size of which, in Kenya, Arabuko-Sokoke Forest (c.24,200 ha.) on the north coast and Shimba Hills National Park (c.9600 ha.) on the south coast retain the greatest forest cover (Tabor et al. 2010). These remnants form an 'archipelago' of isolated forests in an ocean of farmland, and are thought to have once been part of a more-or-less continuous canopy forest that covered the East African coast. Together, the coastal forests provide refugia for many relict animal and plant species, and are characterized by their high degree of endemicity (Burgess et al. 1998), hence their importance for species conservation.

Muhaka Forest is one of many small forest-remnants, several of which, including Muhaka, are kaya, or sacred, forests. Originally thought to have afforded protection against invading Galla warriors, the kaya forests of the Mijikenda people of the Kenya coast also served religious and cultural purposes, and continue to do so (UNESCO 2013). For this reason they have been protected by village elders from encroachment by expanding local populations, resisting both clear-cut conversion to

*Corresponding author. Email: matt.buffington@ars.usda.gov

This work was authored as part of the Contributor's official duties as an Employee of the United States Government and is therefore a work of the United States Government. In accordance with 17 USC. 105, no copyright protection is available for such works under US Law. 
farmland and slower extirpation as trees are felled for firewood and building materials. Muhaka Forest is one of the larger kayas, covering about 150 ha. It is a wet deciduous forest (Waiyaki and Bennun 2000) with an average annual rainfall of $1151 \mathrm{~mm}$ (Foeken 1994). Rainfall is weakly bimodal and concentrated in the 'long rains' of April-June and the 'short rains' of October-December.

As part of a survey and inventory project of Kenyan insects, from 2004-2013, the second author sampled in several coastal forests, including Kaya Muhaka. To date, the project has discovered many interesting new species and provided insights into the geographical distribution of various insect groups, primarily Hymenoptera and Diptera. In fact, these Kenyan insect surveys have supplied several Hymenoptera projects with desperately needed material for understanding Afrotropical species diversity, abundance, and phenology (Buffington and van Noort 2009, 2012; van Noort and Buffington 2013; van Noort et al. 2015). The first author received some samples in 2013 that contained specimens of a genus and species hitherto unknown to science. This unusual wasp is named and described herein: Muhaka icipe Buffington \& Copeland, new genus and species.

\section{Materials and methods}

\section{List of depositories}

NMKE: National Museums Kenya, Nairobi, Kenya (L. Njoroge); SAMC: Iziko South African Museum, Cape Town, South Africa (S. van Noort); USNM: National Museum of Natural History, Smithsonian Institution, Washington, DC, USA (M. Buffington).

\section{Specimen illustration and observation}

The digital illustrations (Figures 1 and 3) were generated by Taina Litwak (scientific illustrator, Systematic Entomology Lab, USDA) from camera lucida pencil sketches of specimens, using scanning electron micrographs for reference to surface sculpture. Digital painting was done using the Adobe CS4 ${ }^{\mathrm{TM}}$ package (San Jose, CA, USA). A Hitachi TM3000 desktop scanning electron microscope (Tokyo, Japan) was used to generate SEM images for Figure 2; specimens were photographed uncoated at 'analysis' voltage, running in 'compo' mode. Colour light microscope images were obtained using the EntoVision multiple-focus imaging system (Frederick, MD, USA) to illustrate diagnostic characters. Methods for generating these photographs follow those in Buffington and van Noort (2009). The resulting images (SEM and LM) were edited in Adobe CS4. All images are available from Morphbank. Direct specimen observation was made utilizing a Leica 205c stereomicroscope (Singapore) with fluorescent desk lamp light sources.

\section{Descriptive format}

Diagnoses focus on easily recognized gross morphologies, and closely related species are distinguished. Terminology for all descriptive characters follows Nielsen and Buffington (2011); surface sculpture terminology follows that of Harris (1979). The following new morphological terms are used.

- Kemnina (Figure 2C): paired overhanging ridges present on the head immediately posterior to the toruli. Derived from Greek (kemnos) for 'overhanging wall or bank'. 


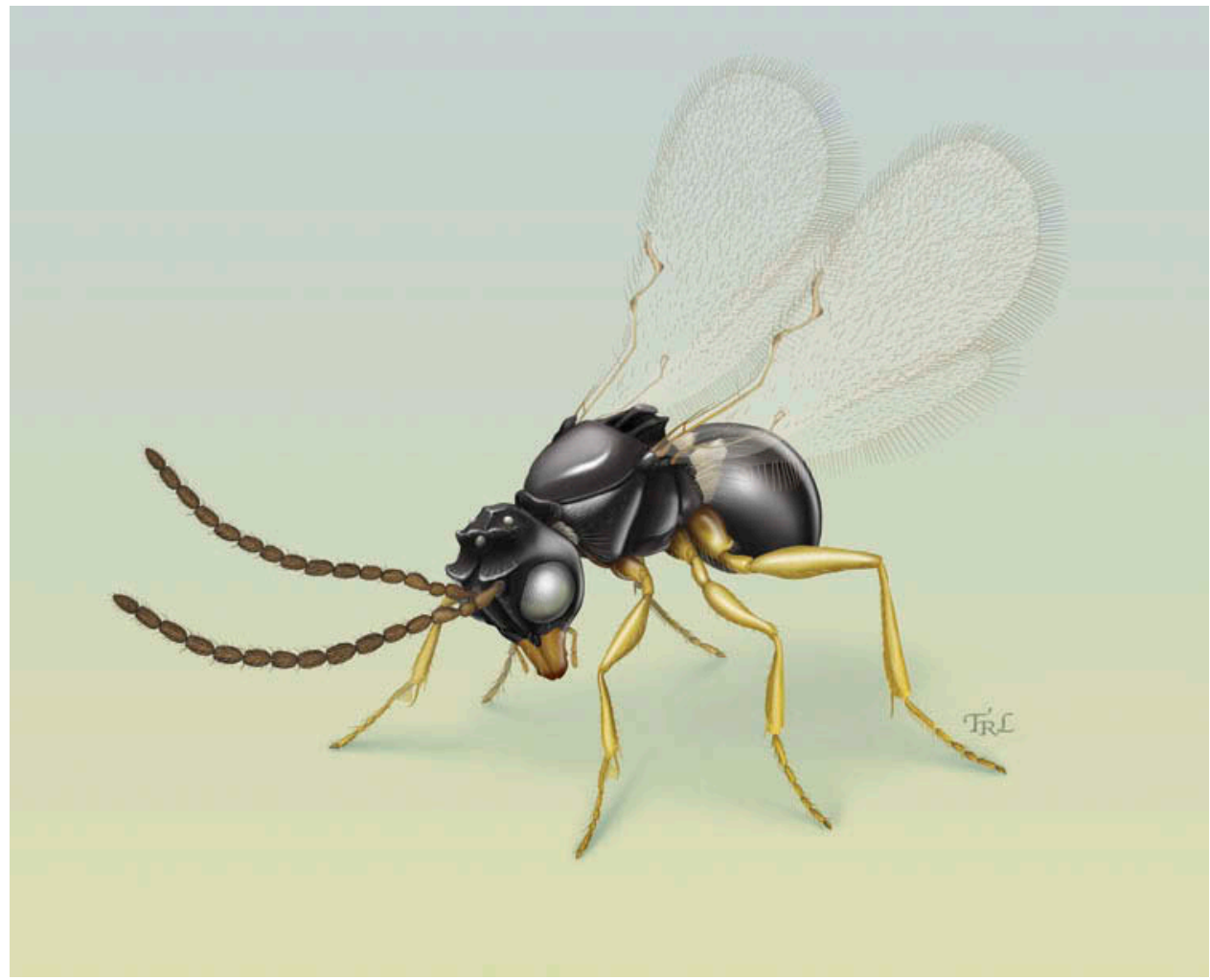

Figure 1. Anterolateral habitus of Muhaka icipe Buffington and Copeland, n. gen., n. sp.

- Ankos (Figure 2C): particular pattern of ornamentation on the vertex, with a semicircular depression circumscribed by anterior and posterior ridge-like elevations. From the Greek (ankos) for 'mountain glen, valley'.

Muhaka Buffington \& Copeland, new genus

Figures 1-3

Type species: Muhaka icipe, Buffington \& Copeland, new species.

\section{Diagnosis}

Unique within Eucoilinae by the possession of a distinct valley-like depression on the vertex (ankos), encompassing the lateral ocelli, and whose anterior ridge directs the anterior ocellus in an anterior orientation; also unique within Eucoilinae is the possession of overhanging ridges over the toruli (kemnina). Superficially, Muhaka may be mistaken for Stentorceps or Nanocthulhu in that these three genera contain species with unusual head ornamentation, as well as relatively large, paddle-like mandibles. However, careful examination of the shape and position of these head characters readily separates Muhaka 

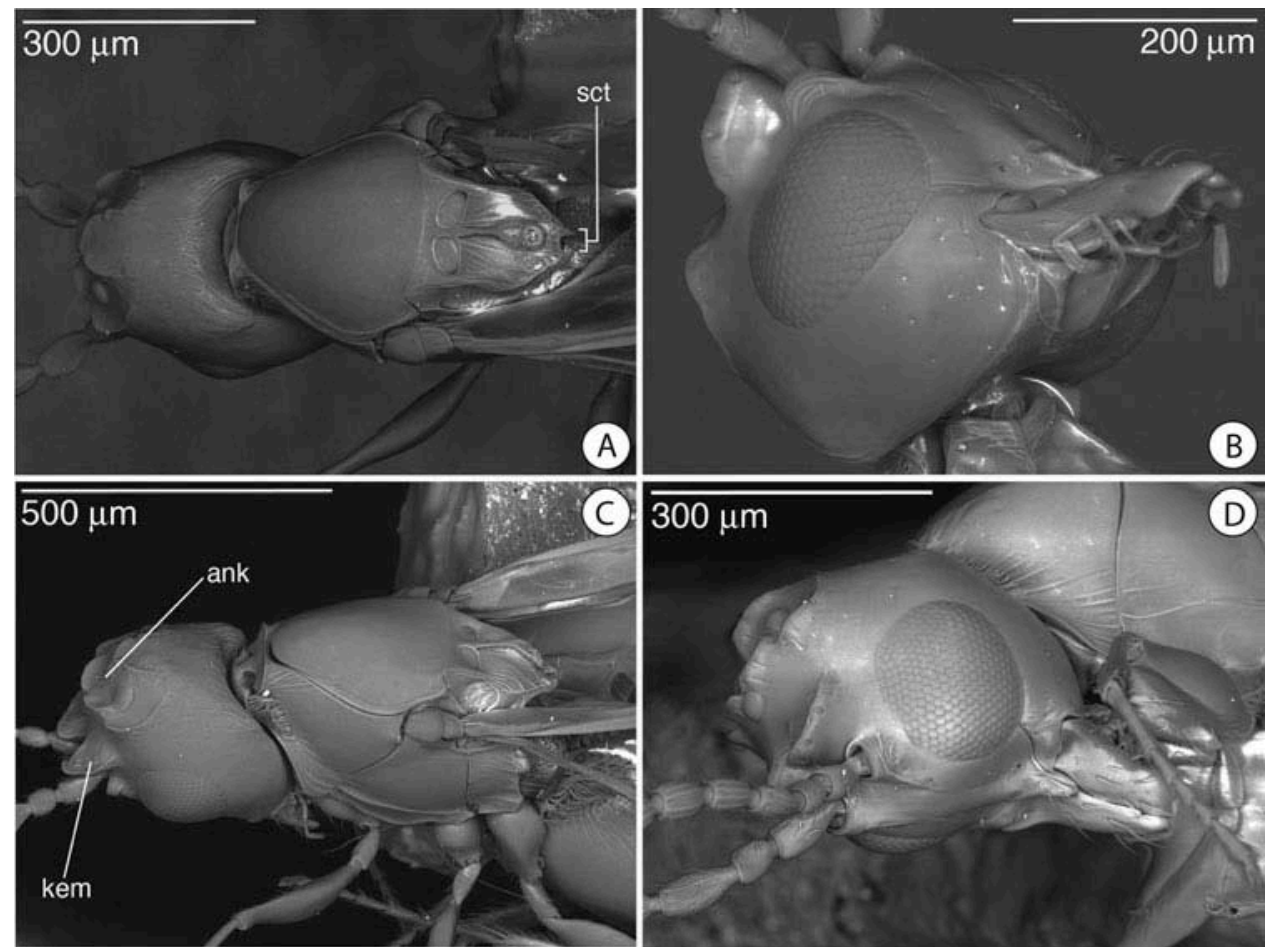

Figure 2. Scanning electron micrographs of Muhaka icipe Buffington and Copeland, n. gen., n. sp. (holotype specimen). (A) Head and mesosoma, dorsal view; (B) head, anteroventral view; (C) head and mesosoma, dorsolateral view; (D) head and pronotum, anterolateral view. Abbreviations: ank, ankos; kem, kemnina; sct, bifurcate posterior margin of scutellum.

from the other two genera. Muhaka clearly belongs in the Kleidotomini, and its fore wing venation is characteristic of the tribe (Figures 1 and 3C). Within Kleidotomini, Muhaka is most similar in appearance to Triplasta species. Both taxa have weak striae on the lateral aspects of the pronotum and along the base of the syntergum of the metasoma. Additionally, in both genera the posterior margin of the metapleuron is distinct and the posterolateral 'face' on the ventral corner of the metapleuron is glabrous. However, in Triplasta species, the metasomal base is glabrous (setose in Muhaka).

\section{Description}

Head. Malar sulcus simple, sinuate, converging towards anterior margin of clypeus, deeply impressed in ventral half immediately posterior to clypeus (Figure 2D); anterior of clypeus pointed, protruding above base of mandibles (Figure 2D); resulting area between malar sulci keel-like (Figure 2D). Orbital furrows absent. Malar space smooth. Kemnina present posterior to toruli, distinctly overhanging toruli when observed dorsally (Figure 2B-D). Ankos present posterior to base of kemnina, resulting in anterior ocellus facing anteriorly (versus dorsally in other eucoilines); lateral ocelli nested within depression of ankos, with short scattered setae present (Figure 2C). Mandibles extremely large, paddle-shaped, roughly 1/3 total length of head (Figures 1 and 2B, D), sub-quadrate, 

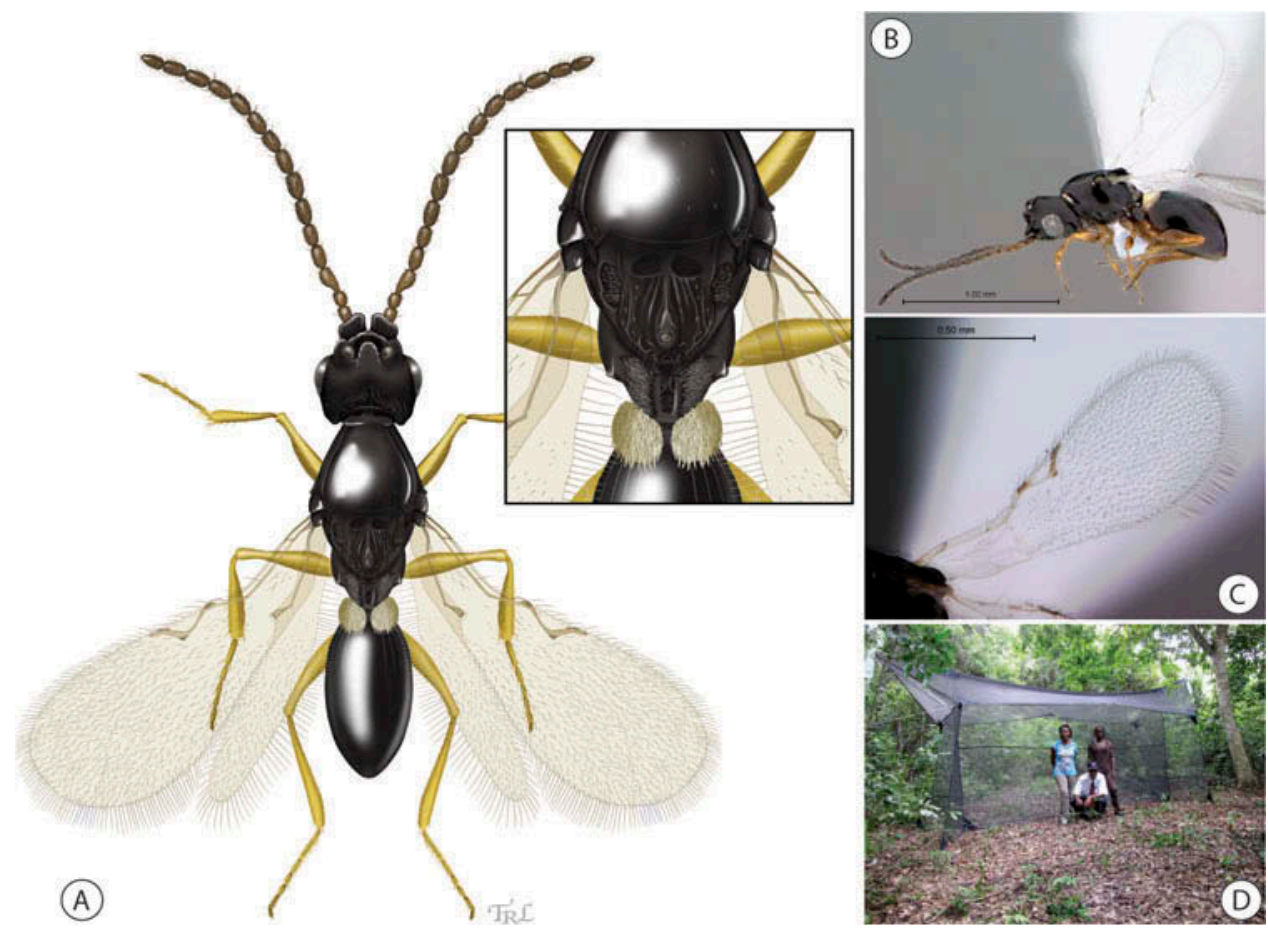

Figure 3. Habitus and habitat images of Muhaka icipe Buffington and Copeland, n. gen., n. sp. (A) Dorsal habitus, with inset of scutellar and propodeal morphology; (B) lateral habitus (holotype specimen); (C) fore wing, bright-field illumination; (D) Muhaka Forest $6 \mathrm{~m}$ Malaise trap.

spatulate in anterior view (Figure 2D); basal mandibular impression present, indicating mandible articulates in longitudinal plane; basal mandibular keel absent.

Antennae. Male: 13 flagellomeres, sub equal in length; multiporous plate sensilla on all flagellomeres; single campaniform sensillum present on distal margin of flagellomeres 4-13; flagellomere 1 distinctly modified, slightly elongate, excavated laterally. Female unknown.

Pronotum. Pronotal plate narrow, with setae present along anterior aspect; dorsal margin rounded; pronotal fovea open laterally; ventral half of pronotal plate extended anteriorly (Figure 2C). Pronotal trough present, ventrad of pronotal plate, deep with broad, confluent setae (Figure 2C). Lateral pronotal carina, pronotal triangle and pronotal impression absent (Figure 2C).

Mesoscutum. Parascutal impression present, incomplete (2C). Notauli, mesoscutal keel, parapsidal ridges, parapsidal hair-lines absent (Figures 2C and 3A). 
Mesopectus. Mesopleural carina simple, distinctly raised (Figure 2C). Precoxal carina of lower part of mesopleuron present, complete (Figure 2C). Surcoxal depression reduced, smooth.

Scutellum. Scutellar plate small, narrow; glandular release pit positioned posteriorly. Dorsal surface of the scutellum longitudinally striate (Figures 2A and 3A).

Metapectal-propodeal complex. Spiracular groove poorly defined, ventral margin absent (Figure 2C). Posterior margin of metapectus gently sculptured, ridged. Metapleural ridge, submetapleural ridge absent; cavity absent along posterior margin of metapleuron, ventral to submetapleural ridge; posteroventral margin slightly drawn out, glabrous, with distinctly flat posterior aspect (Figure 2C). Anterior impression of metepimeron and metepisternum absent.

Wings. Hyaline; setose (Figures 1 and 3A, C). Apical margin complete (not emarginate). Overall wing shape pernaform (Buffington and Sandler 2012).

Legs. Fore- and mid-coxae sub-equal in size, hind coxa twice as long as other coxae; all coxae glabrous; metacoxa without posterior dorsoventral hair line. Femora with sparse setal lines; tibiae and tarsomeres with dense, adpressed setae. Length of metatarsomere 1 slightly less than combined length of remaining metatarsomeres.

Metasoma. Metasoma subequal in size to head and mesosoma (Figure 3A). Base of syntergum with hairy ring, comprised of dense adpressed setae, incomplete dorsally (Figures 2C and 3A); remainder of metasoma glabrous (Figure 3A). Terga posterior to syntergum gradually directed posteriorly. Female unknown.

\section{Distribution}

Afrotropical Region: Kenya.

\section{Etymology}

Genus named in honour of Muhaka forest, the type-locality of the genus; it is a noun in apposition.

Muhaka icipe Buffington \& Copeland, new species.

\section{Diagnosis}

As in diagnosis of the genus.

\section{Description}

As in description of genus with: Head. Nearly glabrous with a few scattered setae on inner orbits of compound eyes, frons, kemnina (torular sculpture) and ankos (central depression on vertex); ocellar hair patches absent (Figure 2D). Genal carina absent, 
but blunt ridge present, glabrous. Longitudinal striae present along vertex, very weakly setose (Figure 2A). Lateral mandibular fold present along basal half of each mandible, containing a single, stout seta (Figure 2B).

Pronotum. Lateral aspect of pronotum smooth, gentle striae present posterior to lateral margin of pronotal plate, as well as ventral to pronotal trough (Figure 2C).

Mesoscutum. Glabrous and smooth except for pair of sparse setal lines along the length of the mesoscutum (in position of notauli) (Figure 3A).

Mesopectus. Upper and lower part of mesopleuron completely smooth, with a few gentle striae anteriorly; glabrous (Figure 2C).

Scutellum. Rim of plate miniscule, translucent; two setae located anteriorly (Figures 2A and 3A); dorsal surface of scutellum bifurcate posteriorly, margined both laterally and posteriorly (sct, Figure 2A). Lateral bars slightly wider than long; ventral lobe present, smooth; auricle lightly setose (Figure 2C). Scutellar fovea elliptical, interior surface smooth (Figure 3A).

Metapectal-propodeal complex. Entire metapectus glabrous except for one to three long setae dorsally. Anteroventral cavity ellipsoidal, setose. Propodeum lightly covered in appressed setae (Figure 2C). Lateral propodeal carinae semi-parallel, slightly divergent, bowed at junction with auxiliary propodeal carinae; auxiliary propodeal carinae indistinct. Nucha heavily setose, deeply crenulate.

Wings. $\mathrm{R}_{1}$ incomplete along anterior margin of wing; marginal cell elongate; trace veins absent, $M$ vein represented by setal line extending to apical margin of wing. Apical fringe medium length, longer along posterior margin.

Metasoma. Hairy ring incomplete dorsally (Figures 2C and 3A). Distinct longitudinal striae present posterior to hairy ring (Figure 3A). Micropunctures absent on syntergum, sparsely present on remaining terga.

\section{Etymology}

icipe in honour of ICIPE, the International Centre of Insect Physiology and Ecology; it is a noun in apposition. ICIPE has been, and continues to be, a leader of entomological research in Africa.

\section{Biology}

Unknown. This species was collected in a $6 \mathrm{~m}$ Malaise trap set inside Muhaka Forest (Figure 3D).

\section{Material examined}

Holotype, male. KENYA, Coast Prov., Muhaka Forest, $52 \mathrm{~m}, 4.32530^{\circ} \mathrm{S}$, $39.52345^{\circ} \mathrm{E}, 6 \mathrm{~m}$ Malaise trap, indigenous forest, 30 May-19 June 2013, R. 
Copeland. USNMENT 01022113. Deposited in NMKE. Paratypes, males: same data as holotype. USNMENT 01022107. Deposited in USNM; KENYA, Coast Prov., Muhaka Forest, $52 \mathrm{~m}, 4.32530^{\circ} \mathrm{S}, 39.52345^{\circ} \mathrm{E}, 6 \mathrm{~m}$ Malaise trap, indigenous forest, 27-30 May 2013, R. Copeland. USNMENT 00917892. Deposited in SAMC.

\section{Discussion}

Muhaka icipe joins a group of eucoiline genera from sub-Saharan Africa that exhibit highly specialized head ornamentation. The other eucoilines are the trichoplastines Stentorceps Quinlan (Quinlan 1984; Nielsen and Buffington 2011) and Nanocthulhu Buffington (Buffington 2012), and to a lesser extent, by the diglyphosematines Nordlanderia Quinlan and Ealata Quinlan (Buffington 2011), as with a few undescribed Afrotropical species of Rhoptromeris Förster and Hexacola Förster (van Noort et al. 2015). With the description of Muhaka, Kleidotomini is now added to this list. To date, the function of these head ornaments is unknown. Buffington (2012) noted a general lack of sexual dimorphism in species of these three tribes (except for typical antennal morphology and genitalic characters), and he hypothesized that these structures are used for escaping from subterranean host puparia. Hence, it is unlikely that Muhaka icipe, being only known from males, is simply the 'male version' of a previously described species; we hypothesize here that when females are eventually recorded, their morphology will be consistent with these herein described males.

Divergence dating of the root nodes of these tribes reported in Buffington et al. (2012) suggests that representatives of the three tribes are separated by some 50-75 million years, suggesting that this head-morphology syndrome has resulted from convergence in the eucoiline body plan. This is perhaps most extraordinary in the convergence of mandible morphology, with the resulting paddle-like mandibles of Stentorceps, Nanocthulhlu and Muhaka (as well as those found in Tyrannoscelio Masner, Johnson and Arias-Penna, and other genera listed in Nielsen and Buffington 2011) directly linked to a specifically 'wedgehead' morphological syndrome. The presence of pyramidal protuberances or clypeal 'scoops' are quite common in Holarctic species of Diglyphosematini, namely Microstilba Foerster, Disorygma Foerster, Sinatra Buffington, and Ganaspidium Weld (Buffington 2011). In fact, there are some Afrotropical species of Rhoptromeris (Trichoplastini) and Ganaspis Förster (Ganaspini) that possess clypeal protuberances, and this morphological feature is not found in species from biogeographic regions outside of the Afrotropics (van Noort et al. 2015). These clypeal features, too, may be linked to emergence from the host puparium. A detailed study of micro-Hymenoptera cranial morphology is presently underway (coordinated by M. Buffington and M. Gates) but no data are yet available for improving our interpretation of these unusual features across the order.

In addition to Muhaka icipe, Muhaka Forest is home to several other interesting animal and plant species. Among insects it is the type locality of Lasiocnemus londti Dikow (Diptera: Asilidae: Leptogastrinae) (Dikow 2007), Vespiodes phaios Dikow (Diptera: Mydidae) (Dikow 2010), and two recently 
described species of Metarbela moths (Lepidoptera: Metarbelidae) (Lehmann 1997, 2008). The rare shrub Keetia lukei Bridson (Rubiaceae: Vangueriieae) (Bridson 1994) was described from Muhaka Forest, and Muhaka and the nearby Gongoni Forest are the only known Kenyan locations of the IUCN red-listed tree Gigasiphon macrosiphon (Harms) Brennan (Fabaceae), known elsewhere only from the Udzungwa Mountains in Tanzania (Luke and Verdcourt 2004). Muhaka Forest is also home to one of very few treehole-crab species, Potomonautes raybouldi Cumberlidge \& Vannini (Brachyura: Potamoidea: Potamonautidae) (Cumberlidge and Vannini 2004). In Muhaka, P. raybouldi was found to occur in a tree-hole estimated to contain over 601 of water (Cumberlidge and Vannini 2004). The same hole, devoid of water during the dry season, was home to a forest cobra (Naja melanoleuca Hallowell) (Cumberlidge and Vannini 2004). A population of the Angola black-and-white colobus (Colobus angolensis palliatus Peters), which is known only from forests in Tanzania and coastal Kenya (Bocian and Anderson 2013), occurs in Muhaka (Anderson et al. 2007).

Additionally, various projects have focused on, or included data from, Muhaka Forest, including studies on dendrolimnetic (treehole) Odonata (Clausnitzer 2002; Clausnitzer and Lindeboom 2002), Lepidoptera biodiversity (Rogo and Odulaja 2001; Lehmann and Kioko 2005), fly pollination of Ceropegia (Apocynaceae: Asclepiadoideae) (Masinde 2004), vertebrate distribution in coastal forests (Azeria et al. 2007), and species richness of birds in Kenyan coastal forests (Waiyaki and Bennun 2000).

Poaching of trees in Kenyan coastal forests is a constant threat due to increased population pressure and the breakdown of traditional values due to the growing popularity of aspects of western culture, and Kaya Muhaka is no exception. For small forest remnants such as that of Muhaka Forest, the immediate danger of ecosystem collapse is real. Recently, illegal tree felling has been detected in Muhaka Forest (RSC pers. obs., R. Pasquet pers. comm.). Hopefully the discovery of endemics such as Muhaka icipe will help build a case for more robust conservation strategies to safeguard these important habitats.

\section{Acknowledgements}

We thank Juliet Muriuki for help with fieldwork in Muhaka Forest. We are grateful to the former Director General of ICIPE, Dr Christian Borgemeister, for supporting our work on Kenyan insect biodiversity and its conservation. MLB was funded by the USDA Systematic Entomology Lab. We thank Mattias Forshage (Swedish Museum of Natural History) and John Noyes (The Natural History Museum) for comments that greatly improved this manuscript. Mention of trade names or commercial products in this publication is solely for the purpose of providing specific information and does not imply recommendation or endorsement by the USDA. The USDA is an equal opportunity provider and employer.

\section{Disclosure statement}

No potential conflict of interest was reported by the authors. 


\section{References}

Anderson J, Rowcliffe JM, Cowlishaw G. 2007. The Angola black-and-white colobus (Colobus angolensis palliatus) in Kenya: historical range contraction and current conservation status. Am J Primatol. 69:664-680.

Azeria ET, Sanmartín I, Ås S, Carlson A, Burgess N. 2007. Biogeographic patterns of the East African coastal forest vertebrate fauna. Biodivers Conserv. 16:883-912.

Bocian CM, Anderson J. 2013. Angola Colobus (Angola black-and-white Colobus, Angola Pied Colobus). p. 103-108. In: Butynski TM, Kingdon J, Kalina J, editors. Mammals of Africa, Volume II. Primates. London: Bloomsbury; 556 pp.

Bridson DM. 1994. A new species of Keetia (Rubiaceae - Vanguerieae) and notes on the Kayas of the Kenya coast. Kew Bull. 49:803-807.

Buffington ML. 2011. Description, circumscription and phylogenetics of the Diglyphosematini Belizin, 1961, and the description of a new genus (Hymenoptera: Figitidae: Eucoilinae). Proc Entomol Soc Wash. 113:239-290.

Buffington ML. 2012. Description of Nanocthulhu lovecrafti, a preternatural new genus and species of Trichoplastini (Figitidae: Eucoilinae). Proc Entomol Soc Wash. 114:5-15.

Buffington ML, Brady S, Morita S, van Noort S. 2012. Divergence estimates and early evolutionary history of Figitidae (Hymenoptera: Cynipoidea). Syst Entomol. 37:287-304.

Buffington ML, Sandler R. 2012. The occurrence and phylogenetic implications of wing interference patterns in Cynipoidea (Insecta: Hymenoptera). Invertebr Syst. 6:586-597.

Buffington ML, van Noort S. 2009. A revision of Anacharoides Cameron, 1904 (Hymenoptera, Figitidae) with a description of a new species. Zookeys. 20:245-274.

Buffington ML, van Noort S. 2012. Revision of the Afrotropical Oberthuerellinae (Cynipoidea, Liopteridae). ZooKeys. 202:1-154.

Burgess ND, Clarke GP, Rodgers WA. 1998. Coastal forests of eastern Africa: status, endemism patterns and their potential causes. Biol J Linn Soc. 64:337-367.

Clausnitzer V. 2002. Reproductive behaviour and ecology of the dendrolimnetic Hadrothemis scabrifrons (Odonata: Libellulidae). Int J Odonatol. 5:15-28.

Clausnitzer V, Lindeboom M. 2002. Natural History and description of the dendrolimnetic larva of Coryphagrion grandis (Odonata). Int J Odonatol. 5:29-44.

[CI] Conservation International. 2013. [cited 2013 Oct 25]. Available from: http://www.conser vation.org/where/priority_areas/hotspots/africa/Pages/africa.aspx

Cumberlidge N, Vannini M. 2004. Ecology and taxonomy of a tree-living freshwater crab (Brachyura: Potamoidea: Potamonautidae) from Kenya and Tanzania, East Africa. J Nat Hist. 38:681-693.

Dikow T. 2007. Taxonomic revision of the genus Lasiocnemus (Loew 1851) (Diptera: Asilidae: Leptogastrinae). Afr Entomol. 15:57-74.

Dikow T. 2010. New species and new records of Mydidae from the Afrotropical and Oriental regions (Insecta, Diptera, Asiloidea). ZooKeys. 64:33-75.

Foeken D. 1994. Climatic seasonality in Kenya with special reference to Coast Province. East South Afr Geogr J. 5:28-43.

Harris RA. 1979. A glossary of surface sculpturing. Occas Pap Entomol. 28:1-31.

Lehmann I. 1997. Metarbela haberlandorum spec. nov., a new moth from Kenya (Lepidoptera: Metarbelidae). Nachrichten entomologischer Verein Apollo. 18:45-53.

Lehmann I. 2008. Ten new species of Metarbelidae (Lepidoptera: Cossoidea) from the coastal forests and the Eastern Arc Mountains of Kenya and Tanzania, including one species from two upland forests. J East Afr Nat Hist. 97:43-82.

Lehmann I, Kioko E. 2005. Lepidoptera diversity, floristic composition and structure of three kaya forests on the south coast of Kenya. J East Afr Nat Hist. 94:121-163. 
Luke Q, Verdcourt B. 2004. An early record of Gigasiphon macrosiphon (Harms) Brenan (Leguminosae-Caesalpinoideae) from Kenya and an update on its conservation status. $\mathbf{J}$ East Afr Nat Hist. 93:75-77.

Masinde PS. 2004. Trap-flower pollination in East African Ceropegia L. (Apocynaceae). Int J Trop Insect Sci. 24:55-72.

Nielsen M, Buffington M. 2011. Redescription of Stentorceps Quinlan, 1984 (Hymenoptera: Figitidae), with a description of five new species. Afr Entomol. 19:597-613.

Quinlan J. 1984. Stentorceps, a remarkable new genus of Eucoilid (Hymenoptera) from Africa. Syst Entomol. 9:479-485.

Rogo L, Odulaja A. 2001. Butterfly populations in two forest fragments at the Kenya coast. Afr J Ecol. 39:266-275.

Tabor K, Burgess ND, Mbilinyi BP, Kashaigili JJ, Steininger MK. 2010. Forest and woodland cover and change in coastal Tanzania and Kenya, 1990 to 2000. J East Afr Nat Hist. 99:19-45.

[UNESCO] The United Nations Educational, Scientific and Cultural Organization. 2013. [cited 2013 Oct 25]. Available from: http://whc.unesco.org/en/list/1231

van Noort S, Buffington ML. 2013. Revision of the Afrotropical Mayrellinae (Cynipoidea: Liopteridae), with the first record of the genus from Madagascar. J Hymenopt Res. 31:1-64. van Noort S, Buffington ML, Forshage M. 2015. Afrotropical Cynipoidea. Zookeys. 493:1-176. Waiyaki E, Bennun LA. 2000. Implications of forest utilisation on bird conservation. Ostrich: J Afr Ornithol. 71:247-256. 